\begin{tabular}{ll}
\hline \hline $\begin{array}{l}\text { MINING AND METALLURGY INSTITUTE BOR } \\
\text { UDK: 622 }\end{array}$ & $\begin{array}{l}\text { ISSN: 2334-8836 (Štampano izdanje) } \\
\text { ISSN: 2406-1395 (Online) }\end{array}$ \\
\hline \hline & \\
UDK $: 379.85 \cdot 006(045)=111$ & \\
\end{tabular}

\title{
QUALITY MANAGEMENT IN THE TOURISM INDUSTRY
}

\begin{abstract}
The traditional approach to the management in the function of quality the tourist industry has not offered the high quality product or service. Namely, dissatisfaction is a response to the managerial approach, reduced customer satisfaction, and small profit. This work points out to a continued access to the quality, necessity of total quality management, levels of TQM implementation and benchmarking. Furthermore, it analyzes the monitoring of quality control to be allocated and coordinated in the organization.
\end{abstract}

Keywords: quality, benchmarking, monitoring, TQM

\section{INTRODUCTION}

The issue of quality is a very important issue in the management theory nowadays. Quality, in this sense, is commonly defined as the ability to meet the needs of consumers in $100 \%$ of time. Undoubtedly, managers in truly progressive organizations are concerned about quality. They understand the basic relationship between a competitive advantage and ability to always deliver quality products and services to its customers.

Total quality management is a comprehensive approach to a continuous improvement the whole organization quality. Every effort done in a context of the total quality management is focused on building quality into all aspects of process, starting from the initial acquisition of resources through the processes and work systems, along the road to the final delivery of products and services to the con sumers. What is important is that this approach invites all to commit to a continuous improvement in all aspects of their work. Not only is the total quality management focused on the needs and interests of consumers, but it also emphasizes the importance of employee involvement in all aspects of improving the quality and delivery. There is no doubt that the total quality management will remain an integral part of the success of the organization in the future.

\section{QUALITY}

According to the well-known project "Profit Impact of Market Strategy", also known as PIMS program, ${ }^{1}$ the quality, in addition to the market share, is the most important determinant of profitability. According to this study, in addition to the

\footnotetext{
*PhD Student at University Singidunum Belgrade, e-mail: mobilshopkm@yahoo.com

** Faculty of Economics Pristina in Kos. Mitrovica, e-mail: todosijevic@ef.uns.ac.rs

**** Emeritus, e-mail: todosijevic@ef.uns.ac.rs
} 
market share, amongst 30 identified factors, it was shown that the quality is in the strongest positive correlation with the return on investment.

Literature defines the term quality very differently. Thus, a well-known researcher in this field, W. Edwards Deming, went so far that the quality is defined as a new religion. ${ }^{2}$ However, all these different definitions and approaches regarding the quality, according to PIMS concept can be summarized in two versions. According to the first version, the definition of quality is based on the internal view on quality. This practically means that the quality is measured by the internal requirements set out in the pre-defined specifications. All activities in this context are aimed at meeting these internal requirements, defined specifications. Hence, this approach to the quality is often treated as an internal view of quality. This approach to the quality usually results by reducing costs through an emphasized control of production, and other activities in the company.

The second, more important approach to defining the quality is the so called external perception of quality. It is based on the consumer's attitude, perception of product value. According to prof. Charles Hill, the quality products in the goods and services are those that are able to satisfy the sense in which they are designed (designed) to do $\mathrm{so}^{3}$ In the other words, the quality of products (services) is determined by a degree of its ability to meet the needs for which it was manufactured and offered. Of course, the ultimate judgment on this possibility, on degree of satisfaction, is given by the consumer himself as incorruptible arbiter whose needs are met by your product or service.

The impact of high-quality products on a competitive advantage of the company is twofold. First, by providing the high quality products, the value of such products is increased in the eyes of customers. In this way, the goal is to gain the customer's loyalty, which is in a direct proportion to the level of product quality. Bidders, who enjoy consumer loyalty have, of course, lower marketing costs, because the customers-service users come back again even without an extensive advertising. Loyalty to a particular company - the hotel is a very effective entry barrier to the other similar customers, which leaves the company rooms in the industry to increase the price of such products, the more it produces services that are differentiated by the quality of the other, have a lower price-elasticity.

Another effect of the high quality companies at a competitive advantage stems from the high efficiency, i.e. lower costs realized from a concern about the quality and content of the offer. The quality hotel offer provides the twofold way contribution to a competitive advantage of the company: through the market situation, that provides a high sales price, and through the internal efficiency, which provides the low operating costs. ${ }^{3}$

Quality management will predominantly determine in the future the attitude of the legal entity towards given future, including the overall quality in itself, benchmarking, attitudes toward competition and a complete and complex attitude to the customerdefined content offerings. This essentially means having an active attitude and affirmation of overall business performance interconnections.

Due to the intensity changes, be they quantitative in terms of offer content that continuous change or increase, or qualitatively competitive emphasis on TQM, it is necessary more than anywhere else, in 
tourism as a propulsive activity, to provide the business process reengineering, which appears as a dynamic tool for renewal, maintenance and increase the economic power of the entity.

Technical and technological development is the result of materialization the results of scientific research activities and we are free, despite the views of some prominent authors, to say that the creative innovation and qualitative relationship to it, is the core of all, where the management activities implement the innovative and research activities into development achievements in the business processes. Information technologies that contribute to the acceleration of scientific, technical and technological progress, have enabled the effective crossfunctional connectivity, organization and business processes, where many activities take place according to a pre-defined software. Thus established - networked processes, carry with them the presumption predefined start and continuous quality. This is applied to the primary, secondary and tertiary sector. Deterioration in the quality and processes is only possible by the controller and manager - a man, because in case of any discontinuity in the activities, the system stops and prevents breakdown. Through the quality, we actually enter into the process of reversibility when things and processes are put back to their original state.

Neither innovation nor imitation must not forget the emphasis on the quality, because the customers, regardless what is the object of purchase or sale, are not ready to respect deviations in the quality.

In terms of development and in terms of business success, it is necessary to give the answers to the Latin next questions: Why? What? How? When? What? Where? Ever?

If we, from the control technology position, being a key to everything even business success, delivered high-quality solutions as a form of answers to the previous questions, we would approach the theoretical concept of absolute organization. But there is no absolute organization, due to the fact that we have an intense effect of changes that occur under the influence of two upcoming operating processes: the competition and technical and technological progress.

Most theories of economic development emphasizes the necessity of technical progress as well as increase the technical progress rate. Certain records of accelerating the technical progressis necessary. This category of development typically requires the capital, entrepreneurial skills, managerial and technical skills and trained labor force, which is generally limited in the underdeveloped countries. Balance of payments problems often prevent the import of these factors to a significant extent, so we have that many less developed countries depend on the assistance program to provide some starting points. ${ }^{4}$ Technical and technological knowledge and skills, complemented by experience, appear as the prerequisites for successful innovation and development response. Here it is necessary to add the need for assimilation and expansion the marketing efforts, which may also occur as a function of business success.

Quality is the position of the present, but it is necessary that the blocks on offer and over the content output bears the vision that should be based on a system of complex social as well as business forecasts, which in turn should serve as an information base for its operational and strategic planning which basically causes planned future. Prognostic futurological attitudes and the strategic choices of carriers of operating activities present a challenge to the intended future, because 
they synchronize with social realities and makes the process of steady functioning whole.

According to a broader understanding the quality, we can present so that TQM is an opportunity to fundamentally improve business functions and business processes in the company, which will result in the superior products that meet thecustomer needs and business results that meet the needs of the top all other stakeholders. ${ }^{5}$

\section{QUALITY AS THE BASIC ASSUMPTION OF THE TOURISM DESTINATION MANAGEMENT}

Quality as a characteristic of not only output, but of the overall course of business activities is a precondition for duration the continuous innovation. By disregarding the quality of the commitments of strategic management, the future of business subject is at risks. Quality becomes the dominant approach to the company future.

The need for continuation the operation alignment and harmonization the management activities, is conditioned by the challenges that come from the environment, and efforts to address these challenges as a chance to reply.

Cultural and historical realities as an expressive and familial tourism resources, and their environment appear as two main factors of success the tourist destinations, taking into account the fact that each branch and each company is a case for itself.

The prescriptive approach views quality as a factor to "create", so as to obtain the maximum strategic advantage.

Modern approach still does not have a unique view on this question. The results will be presented in this work. What is characteristic for it is the emphasis on human resources in tourism, being hardly predictable factors of great importance, because it affects the success of achieving the goals, in particular the quality strategy goals. This should affirm the need for companies to create a close correlation relationship between their resources, their exploitation through the process of putting into use, quality of output and the environment.

Due to its specificity, the prescriptive approach has been more processed and represented in literature, but it will be proven that the solution is an optimal if a successful combination of both approaches is achieved. By combination the research methods, the adequate results will be got, and $d$ the key factors of success will be determined on the basis of the quality as the dominant approach to the modern management.

In the business world, no one is longer prepared to tolerate lack or deviations from quality. An offer, process and its structure, content and outputs on one hand, and assumed demand dynamic on the other side, are subject to defining, standardizing, planning and operationalization the quality system. The quality, inputs and outputs appear as a prerequisite of potential business system success. Starting from the fact that tourism is primarily a business which uses the existing structure design offers of tourist destinations to achieve the positive business success.

Science has found that there is an interaction between system and environment, but it also exists between parts within a single whole. This interaction leads to communication informing each other on the status and changes taking place within them, that leads to the operation of each 


\section{BENCHMARKING AS AN EXTERNAL COMPONENT OF TQM}

other. Components organized like this and their relationship is an organization, as an organized whole of individual parts.

Science has found that the quality of the whole and its way of functioning is conditioned by the way of structuring and linking its parts, as a dynamic structure. This dynamic moves within certain limits, since no system can come into a state of absolute perfection, only chaos is absolute.

Holistic system concept takes into account the objective reality of change. It assumes that the changes are a result of movement, which objectively changes the existing balance, or condition. Therefore, it is determined that everything that exists in the world, is the result of movement, and that nothing is created out of nothing, but out of something. This fact is important to be able to look for the cause of certain changes and directing the movement towards change, which will lead to the specific goals.

Identification of diversity parts in the system, makes it easy to explore the whole. Researchers and designers have to make a grouping of individual differences in the system, but also of certain similarities. So grouped similarities and differences change over time, appear and repeat status changes in the individual segments or parts of the whole. This leads to the conclusion that everything that exists in the world is in all of the changes, which imposes the need for researchers to learn about the characteristics of repeatability, or ways, dynamics and consequences of change.

Holistic is based on the originality of research and findings the most efficient and most effective ways to achieve the set goals.
Benchmarking provides a continuous process of comparison the organization with the others aimed at finding and executing the best practices to ensure the long-term competitive advantage. ${ }^{9}$ Quality revolution or phase in the history of management called the Total Quality Management is based on several important assumptions:

- labeling the consumer and buyer of product, i.e. service users, as the main partner of the business chain;

- orientation towards constant improvement of business, products, services and attitudes towards work;

- active participation of staff in flows of value creation and the use of modern methods and techniques for measuring the business results.

TQM is a special approach to the organization of business based on quality management. ${ }^{12}$ TQM helps to concentrate on what we do wrong and to find ways to improve, but always looking at what and how others are doing, which aims to set the maximum targets that must be achieved. Disorientation on the market represents a failure. ${ }^{10}$ Thus, TQM, which has primarily an internal character, gets from benchmarking a comparable foreign component. It follows that the benchmarking is an integral element of the philosophy of total quality management and continuous improvement the business culture. It is this philosophy and approach to that component of the development of character which is essential to any organization. Differentiation of products and services through the quality leads to competitiveness in designing the best products, ser- 
vices, flexibility and versatility, innovation and time. In both cases, the quality stands as an essential attribute, as the first factor that will lead the company or any organizational system to desired position in the market. Increasing competitiveness of the business system represents one of the ten goals of the business system, which is achieved by introduction the quality systems. These objectives are: ${ }^{6}$

- Design, implementation and certification the quality systems provide a full development of business system and its subsystems. This means that at any moment it is known who, how, when and where activities are carried out related to the optimal functioning of the business system to ensure the quality;

- An increase in profits of the business system;

- Reduction the operating costs;

- Satisfaction and increase the quality of products and services that achieve greater economic effects;

- Provision the quality management from the idea phase to the after use product phase;

- Reducing the risk that the business system does not turnout and fail on domestic and international markets;

- The ability to increase the selling prices on domestic and international markets based on quality;

- An increase in the price of business system when changing the ownership;

- Reduction the cost of products and services that can be realized through the cost reduction
For quality:

- The meeting market demands, and

- Increasing competitiveness of the business system.

Regardless the fact that the emphasis of work is on the control technology in the tourism industry, the validity of this technology will be at a much higher and preferred level if the quality system is included.

Contrary to our views on the evident benefits of TQM, there are also controversies: investing in quality are unprofitable; quality and productivity are incompatible; You cannot have both, let alone to gain the quality over an competitive advantage.

Historically speaking, it was impossible to imagine that they will improve the quality of the way that will increase productivity, because it was thought that it had just to decrease !? Quality begins with the aim of defining management, and is of great importance for the management, because it is, if not the only, then the safest way to evaluate the products and services.

Given that the business in restaurants is one of the infrastructure components of tourism destinations, the previous chart shows the relationships that are characteristic for the spinal column or fish skeleton. This is a diagram "cause - effect" that typically draw teams of people, usually members from the ranks of quality, who are familiar with this problem. Displaying possible causes of the problem in the form allows the team to analyze the problem and find a way of overcoming it. 


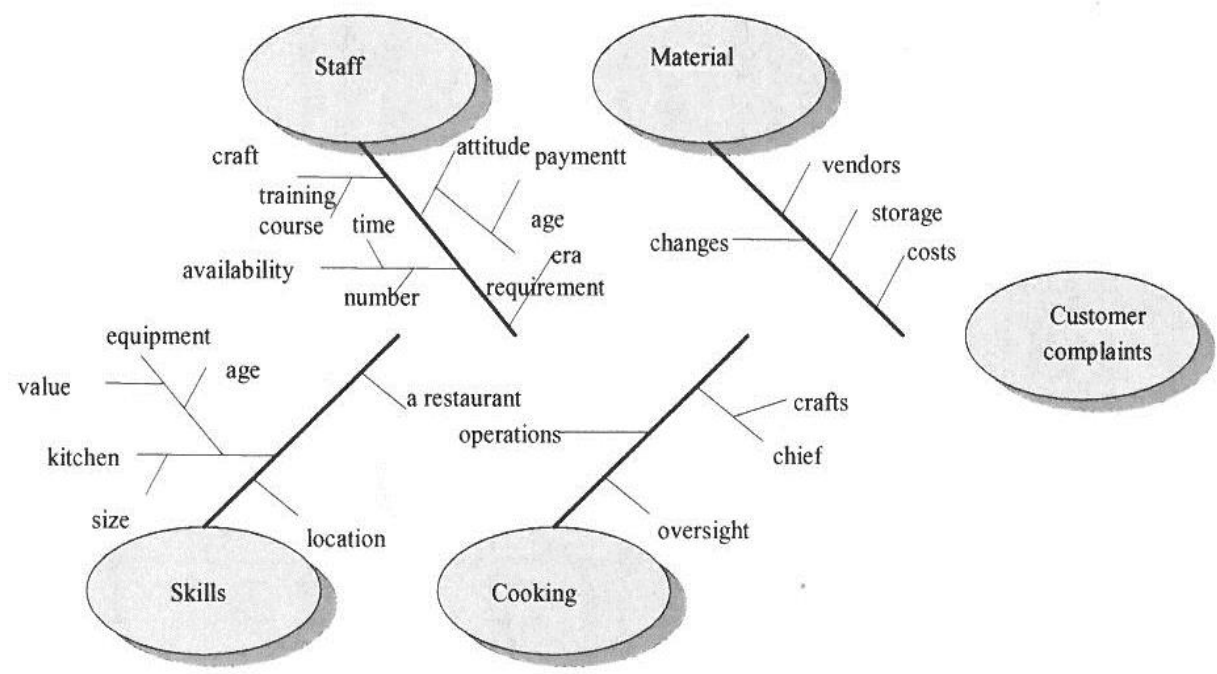

Figure 1 Diagram "cause - effect" to appeal to a hamburger restaurant

\section{QUALITY CONTROL MONITORING}

A lot of efforts are invested in the quality control of tourism and its accompanying activities, especially in hotels and restaurants, especially during provision of services, taking into account the all dimensions of time and stages of the process: before, during and after. It would be reasonable if all the deficiencies were found during a large control. However, the longer faulty process, more time is needed for its detection and much more investment in type and process control.

\section{LEVELS OF APPLYING TQM}

The acceptance of total quality management carries with it a presumption of its application at three levels: the organizational level, process level and business (executive) level.
At the organizational level, the quality refers to meet the basic demands of customers or users of services. Organizations need to seek the answers to the questions used to assist in defining the quality at this level:

- What products and services meet customer expectations?

- Which are not met?

- What products and services are necessary for the guests, and which are not accepted?

- Do guests use the products and services they do not need?

The level of processes (functions) includes the organization functions such as marketing, design and type of service, operations, finance, procurement, sales, etc. As these functions are not independent organi- 
zations and interact, there is a risk to the quality of management and optimization of their activities individually in the company (in the case of a complex enterprise) that can lead to a de-optimization. Managers at this level have to answer the questions such as:

- What are the most important products and services for a guest as a consumer?

- Which processes result in these products and services?

- What are the main inputs into the process?

- In which processes are the most significant effects on the target consumer performance standards?

- What are the most important guests consumers, and what are their needs?

The executive level (level of task determinations) have already certain standards based on the quality and compliance with the customer requirements previously established at the organizational and functional level. These standards include requirements such as the accuracy, completeness, innovation, timeliness, and cost price. For each output of each execution of the tasks may be to ask the question:

- What is common to the requirements of all types of guests - the consumer?

- How will these requirements be measured (standardized for the possibility of planning and control)?

- What are the specific standards for each request?

From the perspective of responsibility, the quality managers for respective level are responsible for it, as the delegation of a task delegated the responsibility. The organizational level focuses on the top management, level of function or processes of middle level managers, level of enforceability or missions of all employees and managers of that level. It may be no-ted that all employees in the organization are involved in the total quality management process.

Acceptance of the concept of total quality helps companies to: ${ }^{8}$

- clearly focus on the needs of their markets,

- achieve superior quality performance in all areas, not only in the quality of products and services,

- simple handling procedures necessary to achieve the quality,

- critically and continuously examine all processes to eliminate the nonproductive activities and losses,

- witness required improvements and develop a performance evaluation,

- understand, in whole and in detail their competitiveness and to develop the effective competitive strategies,

- develop a team approach to the problem solving, develop a good communication and procedures for improvement or confirmation the good work,

- continuous review processes to develop a strategy of continuous improvement - benchmarking.

Quality as a kind of output is essentially a synthesis of a multitude the synchronized activities of a business process.

\section{CONCLUSION}

Quality is the result of technical equipment of operation and technical contemporary means of production, but also the skill and knowledge of workers. Achieving the total quality is a strategic decision, which involves the entire organization. Quality management ceases to be a special function, because it becomes an integral part of the process, so that the structure and organiza 
tion of the whole take responsibility for their quality.

The extent of possible changes in the environment, as a rule, is controlled by a flow of defined scenarios. It is the information that the system - the country - the company receives from the institutional environment in which the macro level is obliged to offer the stability and dynamic environment in which the existence and operations are implemented. The challenges of technological progress and competition, as a rule find their implementation, depending on the characteristics of the created environment. The state usually appears as a synonym for the environment.

None of models or a group of models will reveal the truth about the future, but they can still discover the useful differences regarding our operating environment and certain limitations of our capacity to understand this environment. As we do so, we can make more choices.

It is important to evaluate the synergy effects resulting from the combination of at least two dependencies that amplify or weaken the influential factors. Quality appears as as assumed constant, dependent on several variables.

In addition to the synergistic effects of influential areas, through the control system, the reflection effects may be achieved. These are generally the information societystate system emitted to the environment, impacts and other activities that reflect the environment in another form, and to each other. Reflecting impacts of the system on the environment and the environment on the system should be constantly checked. The extent of possible changes must be analyzed and elaborated in order to be able to prepare and take a position in the strategic orientations that time beyond the fact of ongoing changes.
Quality certainly performs reflection effect and thus affects on gaining the competitive advantages and create the additional value.

The starting assumption of the need quality planning is in the functions of government - in the management organizational system. Quality planning should be viewed as a continuous process and as part of a systematic approach in the company functioning as an organizational system. ${ }^{11}$

The management activities cannot be carried out without a good planning. Planning define ex ante situation, one in which we want to get, and to extend its duration. For management in the tourism industry, it is deemed that the project approach would be suitable, due to the fact that no matter what such heritage constitutes a whole, it must be considered individually, because the act of uniqueness, that each cultural and historical property has and affirms.

\section{REFERENCES}

[1] F. F. Neubauer, Portfolio Management, Concept of Profit Potentials and its Application, Svetlost, Sarajevo, 1991, pp. 73-116 (in Serbian)

[2] M. Walten, The Deming Management Method, A Perigee Book, 1986, pp. 58

[3] C. W. L. Hill, G. R Jones, Strategic Management Theory, An Integrated, Approach, Fourth Edition, Houghton Mifflin Company, Boston, 1998, pp. 116, pp.130.

[4] Pearce D. W. MacMillan Dictionary of Modern Economics, 4 Ed. 2003, pp. 480

[5] Heleta M., Quality Management, Sigidunum, Belgrade, 2008, pp.28 (in Serbian)

[6] Mitrović Ž., Quality and Management, Institute of Agricultural Research, Belgrade, 1996, pp.19 (in Serbian) 
[7] Brache A.P. and Rummler G.A. Three Levels of Quality, Quality progress 21, No. 10, October 1988.

[8] Oakland J.: Total Quality Management, Grower Handbook of Quality Management, Edt. Denis Lock, Gower Press, London, 2005.

[9] Đuričić Z., Jovanović K., Đuričić R., Benchmarking as an Instrument of Modern Management, International Scientific Conference on Management 2010, Kruševac, pp.138 (in Serbian)
[10] Todosijević R., Todosijević-Lazović S., Global Strategies in a Function of the Hotel Business Quality, IX ${ }^{\text {th }}$ International Scientific - Expert Symposium, Hotel House 2013, Zlatibor, pp. 42 (in Serbian)

[11] Glušica Z., Implementation of TQM, Quality Mobes, (2001), pp. 71 (in Serbian)

[12] http://www.cqm.rs/2010/pdf/37/04.pdf 